\title{
La avenida Alfonso Ugarte, otra vez muralla de Lima*
}

\author{
Alfonso Ugarte avenue, once again the wall of Lima
}

\author{
Adolfo Córdova** \\ Universidad Nacional de Ingeniería \\ Recibido: 9 de diciembre de 2019 \\ Aceptado: 6 de enero de 2020
}

El espacio que ocupa la avenida Alfonso Ugarte tiene vocación (¿o maldición?) de muralla. Durante decenas de años virreinales, hecha de hiladas de piedra asentadas con mortero de cal y arena (proporción 1:3), coronada por almenas, tuvo en tiempos republicanos casi un siglo de pretensiones parisinas, para retornar recientemente a su anterior misión de muralla, edificada esta vez con tramos de mala arquitectura metálica y largas hiladas de maloliente $\mathrm{CO}_{2}$ (anhídrido carbónico), asentadas con ruidos de claxon, motores y de silbatos policiacos (proporción 3:1).

La avenida Alfonso Ugarte, espacio de mis juegos infantiles, de mis paseos juveniles, de mis encuentros amicales, inaugurada por Leguía en 1918, conocida antes como ancha alameda con el nombre de avenida de Circunvalación, fue primero el largo tramo oeste ocupado por la muralla de Lima, construida en tiempos del virreinato para defender la ciudad de posibles ataques de piratas y filibusteros, tan temidos en esas épocas. Hoy ya no es el espacio que conocí de niño, gocé de adolescente, viví de joven. Por obra y gracia de dos alcaldes es otra vez una muralla. Ya no de gruesa y alta albañilería, sino de mediocres edificaciones metálicas a guisa de andenes y paraderos, y recorrida por cercos alambrados entre los que circulan rápidos vehículos conformando, en conjunto, una infranqueable barrera. Es decir, una nueva muralla.

\footnotetext{
* Antecedentes del documento. Texto escrito en julio de 2003, actualizado en diciembre de 2019. La excelente obra Planos de Lima. 1613-1983, de Juan Gunther, editada durante el período del alcalde Eduardo Orrego, ha servido de guía para seguir los cambios de la avenida Alfonso Ugarte. Las fotografías antiguas han sido obtenidas de internet.

** Adolfo Córdova Valdivia. Ingeniero en la especialidad de arquitectura (Departamento de Arquitectura, Escuela de Ingenieros, hoy Facultad de Arquitectura, Urbanismo y Artes, Universidad Nacional de Ingeniería). Doctor Honoris Causa (Universidad Nacional de Ingeniería).
} 


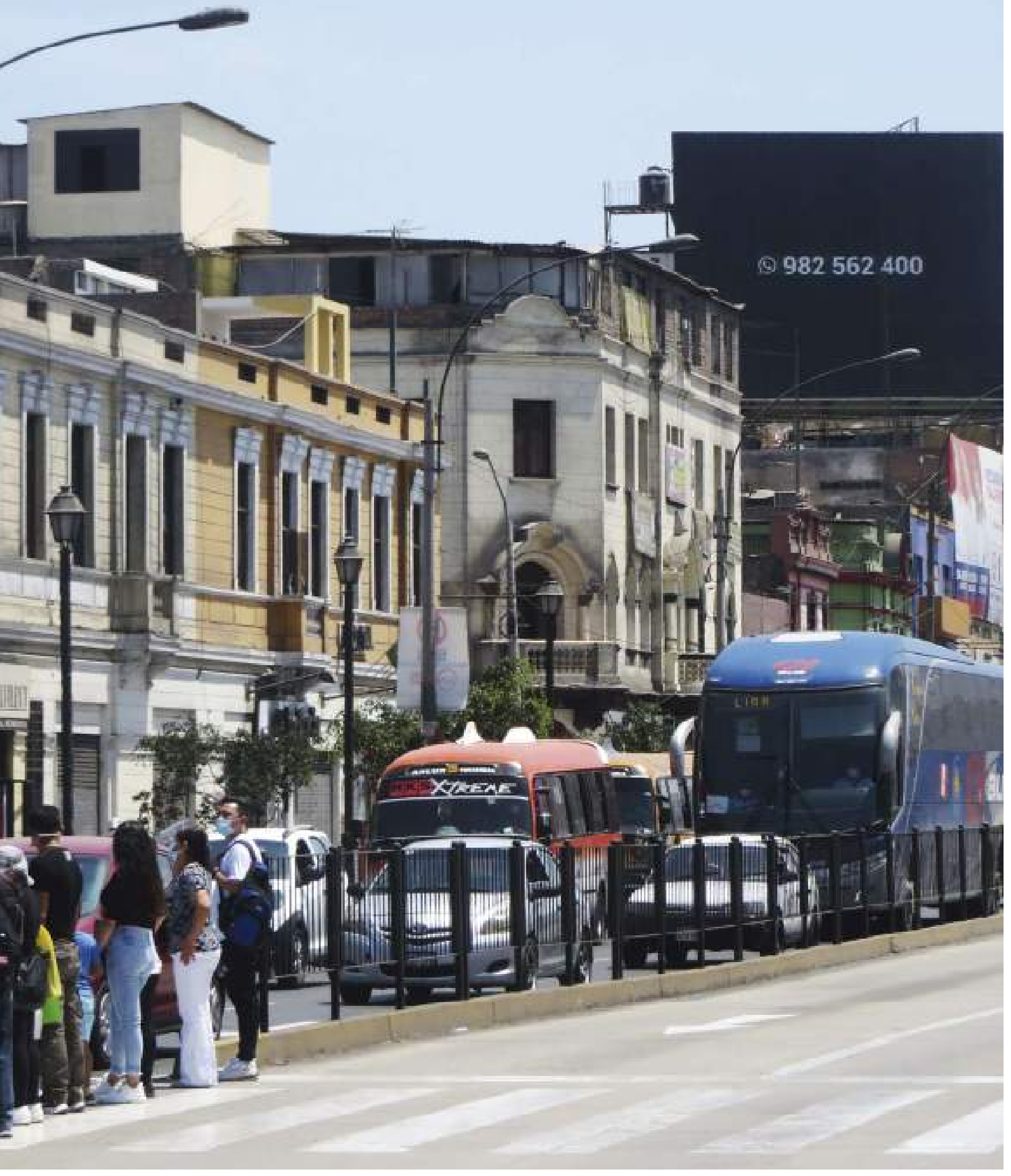


Después de un inolvidable viaje por mar, pues no existía aún la carretera al sur, llegamos a Lima, a comienzos de 1935, directamente a la avenida Floral, que nace en la avenida Alfonso Ugarte, justamente frente a la puerta principal del Cuartel Sexto. Recuerdo que quien me la mostró lo hizo, subrayando con orgullo de limeño, que era "la única avenida de cuatro pistas, que había sido hecha por Leguía y que, como en Europa, tenía baños públicos".

Las cuatro pistas estaban separadas por tres bermas, de las cuales la central era la más importante, quizás de unos 7 metros de ancho, mientras que las otras dos, sembradas totalmente con césped y con árboles regularmente espaciados, no medían más de metro y medio. (Imagen 1)
El jardín que recorría la berma mayor estaba acompañado, a uno y otro lado, por veredas en cuyo límite interior unas bancas de mármol blanco, duro y frío, estaban dispuestas, de trecho en trecho. (Imágenes 2 y 3) El verdor de este jardín me ha dejado un recuerdo especial, cuando tres o cuatro años más tarde, descubrí asombrado, con mis recientes anteojos de estreno, que su color no era uniforme, plano y apagado, como lo veían mis ojos de miope, sino que estaba formado por muchísimas pequeñas hojas verdes, verdes y brillantes de variados tonos que ahora sí podía distinguir nítidamente, independientes unas de otras. Y qué claros me parecieron los letreros de los bazares Ichikawa y Yogui, y el de la botica Garrido entre ellos, tres

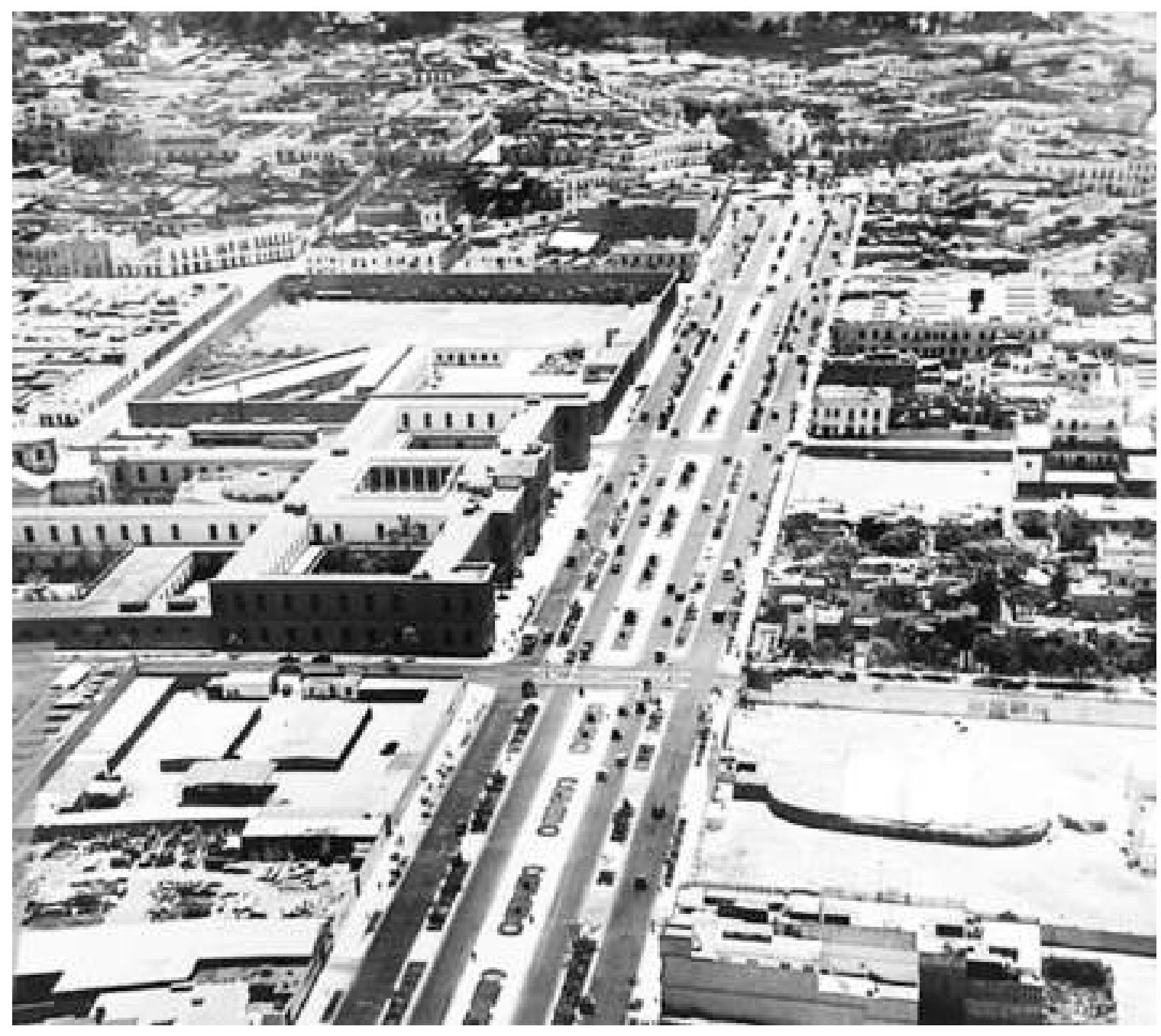

Imagen 1. Vista aérea de la avenida Alfonso Ugarte. Al fondo, la plaza Bolognesi. A la izquierda, Cuartel El Sexto y Colegio Guadalupe. A la derecha, de atrás para delante, transversales de la avenida A. Ugarte: avenida España, calle Floral (luego Portugal), avenida Bolivia, jirón Recuay y avenida El Progreso (luego Venezuela).

Fuente: http//www.facebook.com.limantigua. 


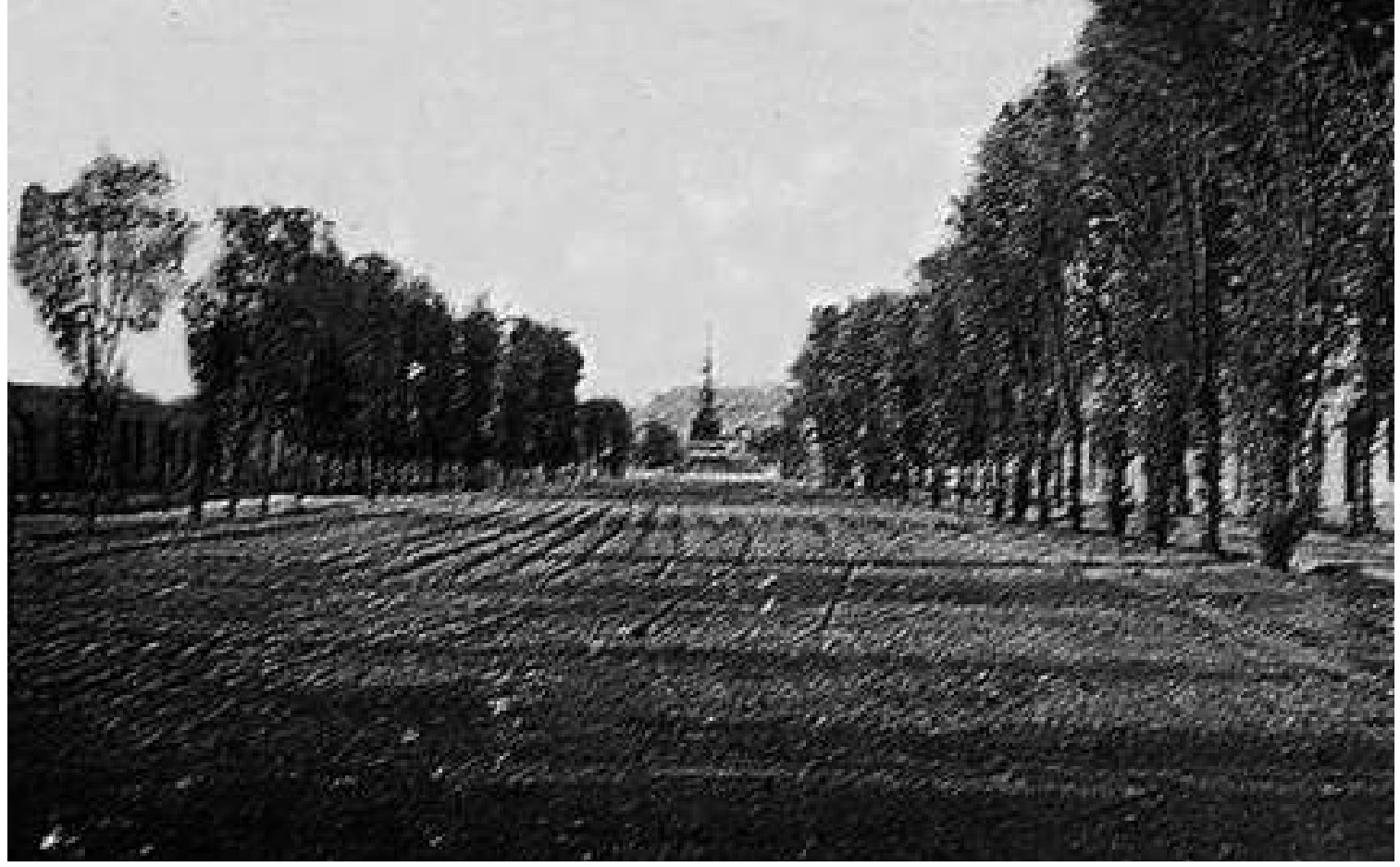

Imagen 2. Av. de Circunvalación, Lima (luego Av. Alfonso Ugarte). Fuente: http//www.limalaunica

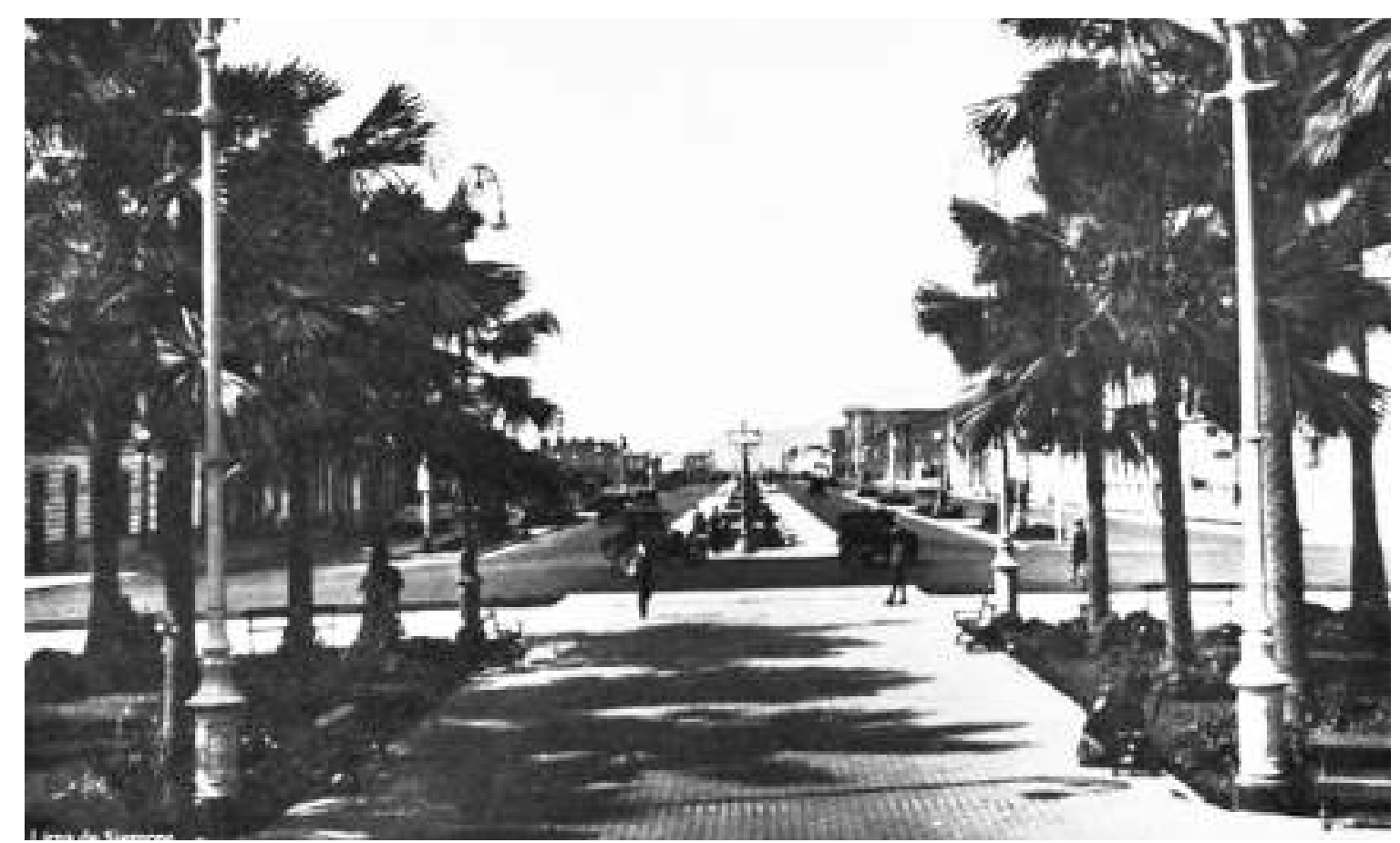

Imagen 3. Av. Alfonso Ugarte, Lima. 1927. Fuente http//www.limalaunica

locales que ocupaban la planta baja de un sector de "la Quinta" situada entre las avenidas Floral y casi España y cuyo pasaje de ingreso estaba junto a la citada botica. En la esquina con la avenida España una casa sobre elevada de la vereda -después supe que la diseñó Héctor Velarde- era local de la Asociación Guadalupana.

La avenida Alfonso Ugarte tenía en efecto baños públicos que, cuando la conocí, ya estaban clausurados. Ubicados en la berma central, ocupaban una edificación alargada que sobresalía del nivel de la acera no más de metro y medio, pues los locales -eran dos (uno para hombres y otro para mujeres)- estaban en semisótano, de modo que para acceder a ellos había que descender la escalinata correspondiente, una en cada extremo del bloque. El techo, accesible desde ambos lados, funcionaba como una glorieta rectangular enmarcada por una balaustrada. (Imágenes 4 y 5) Esta edificación de color gris, como las aceras y las fachadas de dos pisos frente al Sexto -que en cambio era de ladrillo visto- estaba en el eje mismo de la avenida Floral y de la puerta de ese 


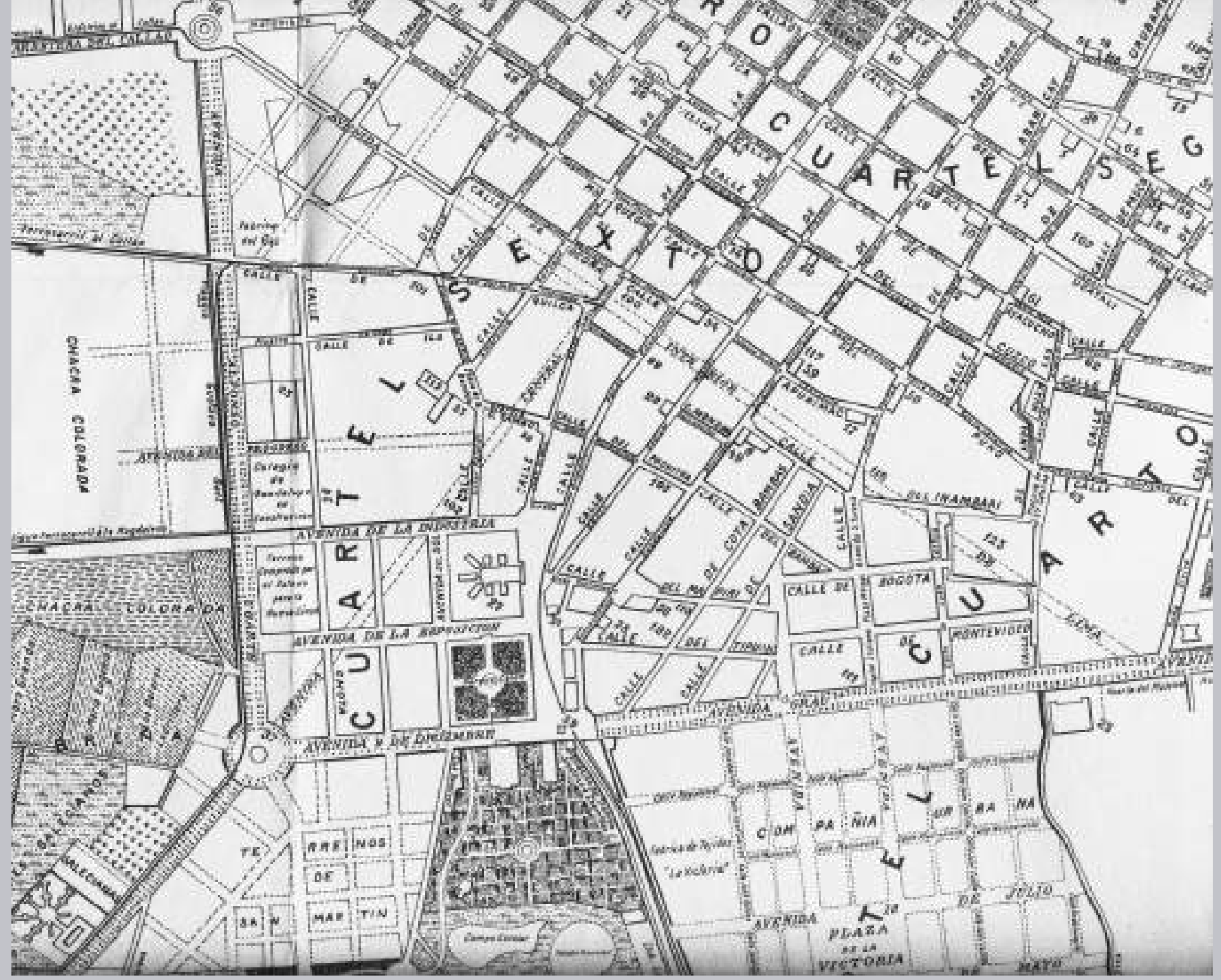

Imagen 9. Plano de Lima. 1904. Santiago Basurco (Fragmento). Fuente: Gunther, J. (1983)

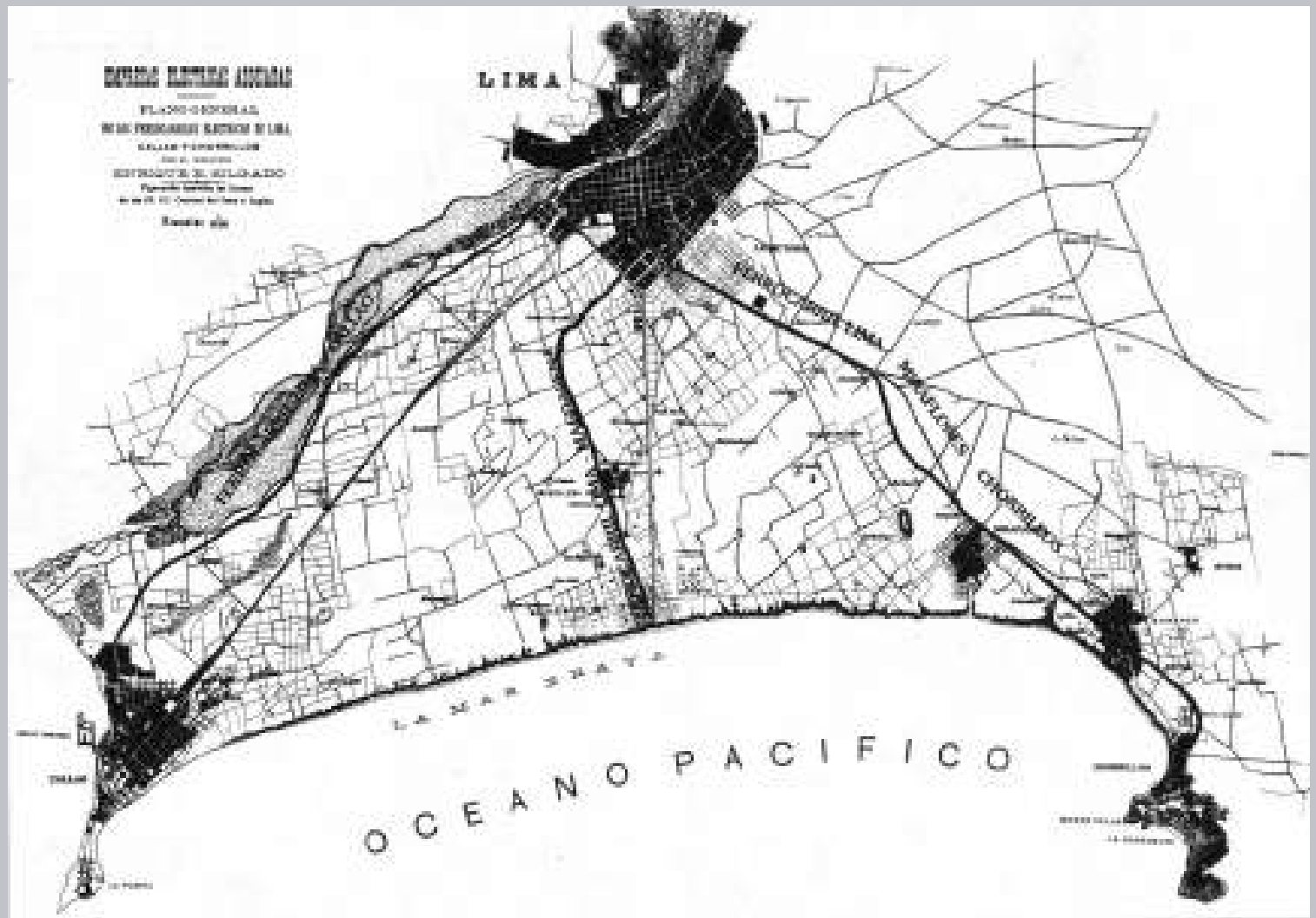


En el Plano de Lima, rectificado por Manuel A. Fuentes en 1858, aparece el ferrocarril al Callao, cuya salida por la muralla corresponde aproximadamente a la Portada de San Jacinto, hoy Quilca, como digo antes. (Imagen 6)

Pero es en el plano de Lima de 1880 , hecho por P. V. Jouanny, que no se muestra ya la muralla, salvo los baluartes en la zona del Cercado, existentes hasta hoy. Aparecen en cambio la Plaza 2 de Mayo ("La columna del 2 de mayo") y la avenida de Circunvalación, primer nombre de Alfonso Ugarte, mostrando los cruces del ferrocarril al Callao (Portada de San Jacinto) y del ferrocarril a la Magdalena (Portada de Juan Simón). Figura también la prolongación hacia el norte, que después se llamó avenida Bolognesi, incluyendo el amplio espacio que es hoy la Plaza Unión. Con semejante indicación al de la avenida Circunvalación se muestra el tramo de lo que es ahora el Paseo Colón y la avenida Grau (entre las Portadas de Guadalupe y de Cocharcas), pero no hay aún continuidad con nuestra avenida. (Imagen 7)

Cosa que sucede poco después, como indica el plano que en 1896 elaboró el Cuerpo Técnico de Tasaciones y publicó en 1899. Allí la futura avenida Alfonso Ugarte y el futuro Paseo Colón tienen el nombre común de "avenida de Circunvalación" y se encuentran en ángulo recto. No existe aún la Plaza Bolognesi, pero sí, en el vértice, el nacimiento de la "avenida de la Magdalena", que sería después la avenida Piérola y más tarde la avenida Brasil. (Imagen 8)

Precisamente con ese segundo nombre aparece en el plano que en 1904 hiciera el ingeniero arquitecto Santiago M. Basurco. Este documento es de gran importancia para el tema de esta nota. Con su actual nombre aparece por primera vez la avenida Alfonso Ugarte, con sus 1700 metros entre las Plazas 2 de Mayo y Bolognesi, así como su prolongación de cerca de 500 metros hacia el norte, incluyendo la Plaza de la Unión. Se hace evidente, además, no solo la importancia que empieza a tener la avenida -en cuyo frente el Colegio Guadalupe figura en construcción con diseño del propio Basurco y, con terreno asignado, la nueva cárcel que después fue el famoso Sexto-, sino que apa- recen ya las primeras manzanas de la zona industrial, con la "avenida de La Unión" como eje, las edificaciones que rodean la Plaza 2 de Mayo, el trazo en proyecto de la avenida Progreso y el de la llamada avenida de la Industria, la actual avenida Bolivia, unidas por una paralela a Alfonso Ugarte, conformando entre las tres el boceto inicial de la urbanización Chacra Colorada. Al sur de la avenida 9 de Diciembre, en la zona de la hacienda Santa Beatriz, figura el camino (futura avenida Salaverry) que, pasando junto al hipódromo se prolonga hasta la Escuela de Agricultura en tanto que, más al este, el proyecto del barrio La Victoria aparece más definido, hasta con la nomenclatura de las calles que se conserva actualmente, delimitado por el ferrocarril a Chorrillos y el río Huatica. El desborde, más allá de las antiguas murallas, se ha iniciado y ya no se detendrá, como lo anuncia, o más bien lo provoca, el hecho de haberse suprimido el calificativo "circunvalación" a las avenidas, tipo alameda, que invitan al desarrollo de sus dos frentes y aspiran a convertirse en ejes de circulación. (Imagen 9)

De hecho, por esta misma fecha puede verse en el plano de la Empresa Eléctrica de 1908, las líneas del servicio de tranvía eléctrico con que se dotó a la capital, una de las cuales recorre la avenida Alfonso Ugarte, circunda la Plaza Bolognesi y toma la ruta de la Magdalena, mientras otra rodea parcialmente la Plaza 2 de Mayo para dirigirse al Callao. (Imagen 10)

Pero si el desborde se inicia en la primera década del siglo $\mathrm{XX}$, la expansión de la ciudad, más acusadamente hacia el sur que hacia el oeste, se da en los años siguientes. Para el centenario de la Batalla de Ayacucho las dos plazas circulares, 2 de Mayo y Bolognesi, lucen ya totalmente circundadas de edificaciones con un afrancesado diseño que les confiere gran unidad. Entre ellas, en el lado este, la nueva cárcel con el muro perimetral listo está en construcción, el Colegio Guadalupe está concluido (imagen 11), hacia el norte el Estanco del Tabaco y la Empresa de Gas llenan las manzanas centrales, mientras en los extremos, junto a las plazas, pequeños lotes son dedicados a vivienda. En el otro frente, cerca de la Plaza 


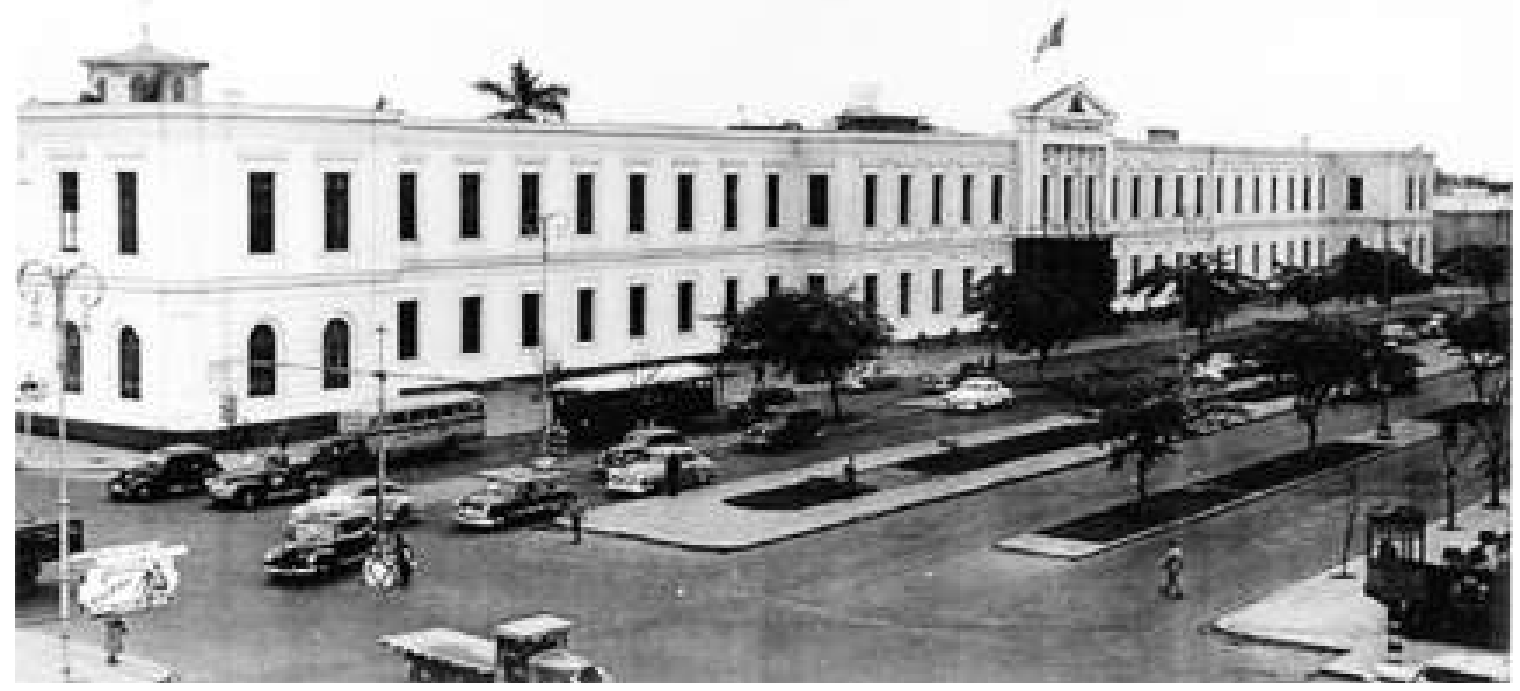

Imagen 11. Colegio Nuestra Señora de Guadalupe. Diseño: Santiago Basurco. Fuente http//www.limalaunica.pe

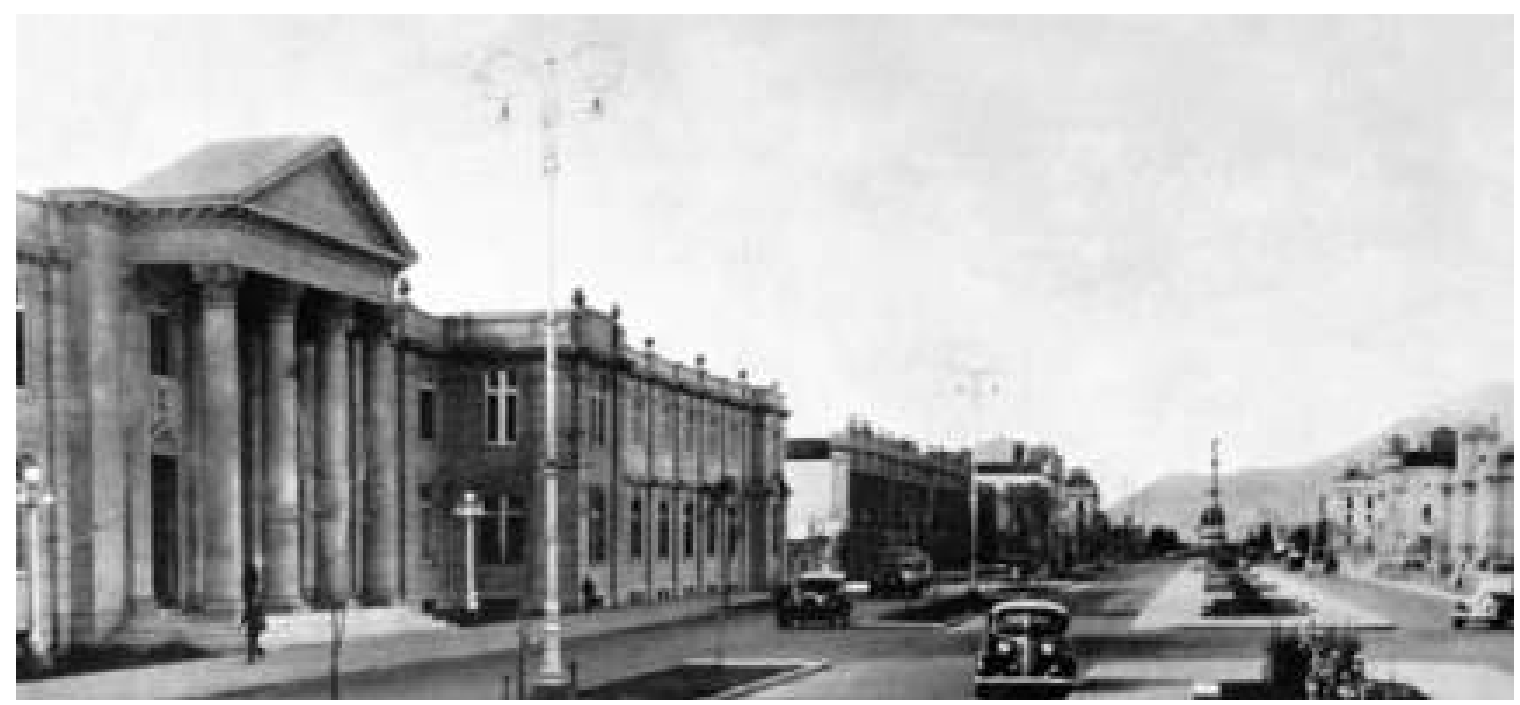

Imagen 12. Hospital Arzobispo Loayza. Diseño: Rafael Marquina. Fuente http//www.limalaunica.pe

2 de Mayo, el Museo Nacional de la Cultura Peruana y la Estación de Tranvías preceden al Hospital Arzobispo Loayza, cuyos pabellones principales se deben al arquitecto Rafael Marquina (imagen 12). Frente al Colegio Guadalupe, la quinta Boza reúne un grupo de casas alrededor de un parque interior. $Y$ en la manzana inmediata a la Plaza Bolognesi, subdividida en tres por dos pasajes, edificaciones para casas habitación ocupan todos los lotes.

Pero en esta década el proceso se acelera como lo atestigua el plano del Cuerpo Técnico de Tasaciones de 1927. En el lado oeste de Alfonso Ugarte que acabamos de citar, dos urbanizaciones quedan planteadas: la urbanización "Garden City" limitada por el triángulo que forman dicha avenida con Arica y Bolivia y la urbanización Chacra
Colorada que se desarrolla entre esta y Quilca (límite con el costado del Hospital Loayza) y llega hasta el río Maranga.

De otro lado, un período de obras públicas, gracias al Fondo Pro-Desocupados, permite una vigorosa actividad constructora del Estado que estimula también a la actividad privada. La avenida Alfonso Ugarte, en esta etapa que corresponde al gobierno de Leguía, adquiere efectivamente su trazo de cuatro pistas, sus dos núcleos de servicios higiénicos públicos que, desgraciadamente, no supieron administrarse y amplias aceras al pie de las edificaciones. Trazo que seguramente incita a su complementación edilicia con locales tanto institucionales como de vivienda.

Si después de este recorrido por el tiempo, volvemos a la avenida que conocí en 
los años de las Olimpiadas de Berlín, de las "coboyadas" con Tom Mix y Gene Autry, el vaquero cantor, y de la trágica muerte de Carlos Gardel (sucesos que me llevaron a dibujar al carbón los retratos, malos pero sentidos, de Lolo Fernández, de algún cow-boy y del cantor de Buenos Aires), si regresamos a esa época, decía, puedo recordar, además de los edificios antes señalados, el Museo Nacional de la Cultura Peruana, de arquitectura tiahuanacoide, ganado en concurso por el arquitecto Malachowski; el Instituto Nacional de Enfermedades Neoplásicas, diseñado por Guillermo Payet, situado frente al Hospital Arzobispo Loayza; el Colegio Nacional de Mujeres Rosa de Santa María y, cercano a la Plaza Bolognesi, el cine Ritz y al frente el único edificio alto, de ocho o diez pisos, diseñado por Paul Linder. Los demás edificios de vivienda de toda la avenida obedecían a un patrón que, con pocas excepciones, consideraba cada lote totalmente ocupado en dos niveles. Se accedía al segundo por escaleras de mármol o madera, cuyas habitaciones eran iluminadas desde el corredor que dejaba un pozo de luz para la iluminación de las habitaciones del primer piso. En este, dicho pozo ampliaba el área del corredor conformando una especie de patio. El pozo, común a ambos niveles, estaba protegido por una farola. La iluminación y ventilación aceptables en el piso alto, eran insuficientes en los bajos. Muchas de estas casas aún subsisten.

La propia Plaza Bolognesi, con la estatua del héroe muriendo abrazado a la bandera después de haber disparado el último cartucho, en la cima de su alta base rodeada de esbeltas y hermosas palmeras, era un lugar de encuentro y esparcimiento. (Imagen 13) Allí se patinaba, se daba vueltas en bicicleta y se aprendía a fumar. Allí, por ejemplo, nos citamos los alumnos de cuarto de media un día de primavera en que acordamos todos "hacernos la vaca". Nos costó asistencia al colegio los cuatro sábados siguientes.

Hubo un tiempo, a comienzos de la década de 1940, en que después de la misa dominical en la vecina iglesia de Maria Auxiliadora o luego del concierto de la Orquesta Sinfónica Nacional en el Campo de Marte, se puso de moda el paseo juvenil, con fines de enamoramiento, de chicas y chicos "clasemedieros" procedentes de diversos barrios y aun de los llamados balnearios del sur, en las dos primeras cuadras de Alfonso Ugarte, entre la Plaza Bolognesi y la esquina de la avenida Floral (que después pasó a llamarse Portugal). ${ }^{1}$ Este ir y venir de sonrisas y miradas, entre siete y nueve o diez de la noche, en esa amplia acera duró unos cuatro o cinco años. Poco a poco la costumbre emigró al Paseo Colón y de allí, tiempos después, se trasladó al parque Salazar de Miraflores, adonde ya no fui por ser "mayorcito" y estar ya casado.

Un recuerdo traumático de ese tramo de Alfonso Ugarte es el del asalto a los japoneses. Cuando Estados Unidos, durante la Segunda Guerra Mundial entró en guerra con el Japón, nuestro presidente Manuel Prado y Ugarteche, quien no quiso ser menos, declaró la guerra al Eje y ordenó la prisión y expulsión de japoneses y alemanes. No sé si antes o después de esta orden, de pronto un día, en un par de horas o menos, una horda vociferante entró a los bazares de Yogui y de Ichikawa y cometió un saqueo tan veloz y completo que no dejó sino destrozos, con el pavor del chino de la esquina de la avenida Floral que cerró sus puertas, "no lo fueran a confundir con japonés". Como es sabido los nipones y alemanes apresados fueron enviados a los Estados Unidos donde, concentrados en campos especiales, vivieron hasta la finalización del conflicto, en que fueron canjeados.

Por entonces ya no existía la línea de tranvía a lo largo de toda la avenida, como aparece en los planos descritos. Solo había una línea que venía del centro por la avenida España, recorría la primera cuadra de Alfonso Ugarte, daba la vuelta a la Plaza Bolognesi y en trazo paralelo, volvía por donde llegó. Pero de la plaza salían dos ramales, uno de ida a la Magdalena y otro de vuelta. Así era posible viajar a la Magdalena, hasta San Miguel o bien tomar "el urbanito" que rodeaba la Plaza para ir al centro o para conectarse, usando el mismo boleto, con el tranvía a Chorrillos o con el de La Punta. Estas dos líneas, de coches grandes, en "horas punta" iban acoplados de a dos. Las líneas de ómnibus que recorrían toda la avenida 


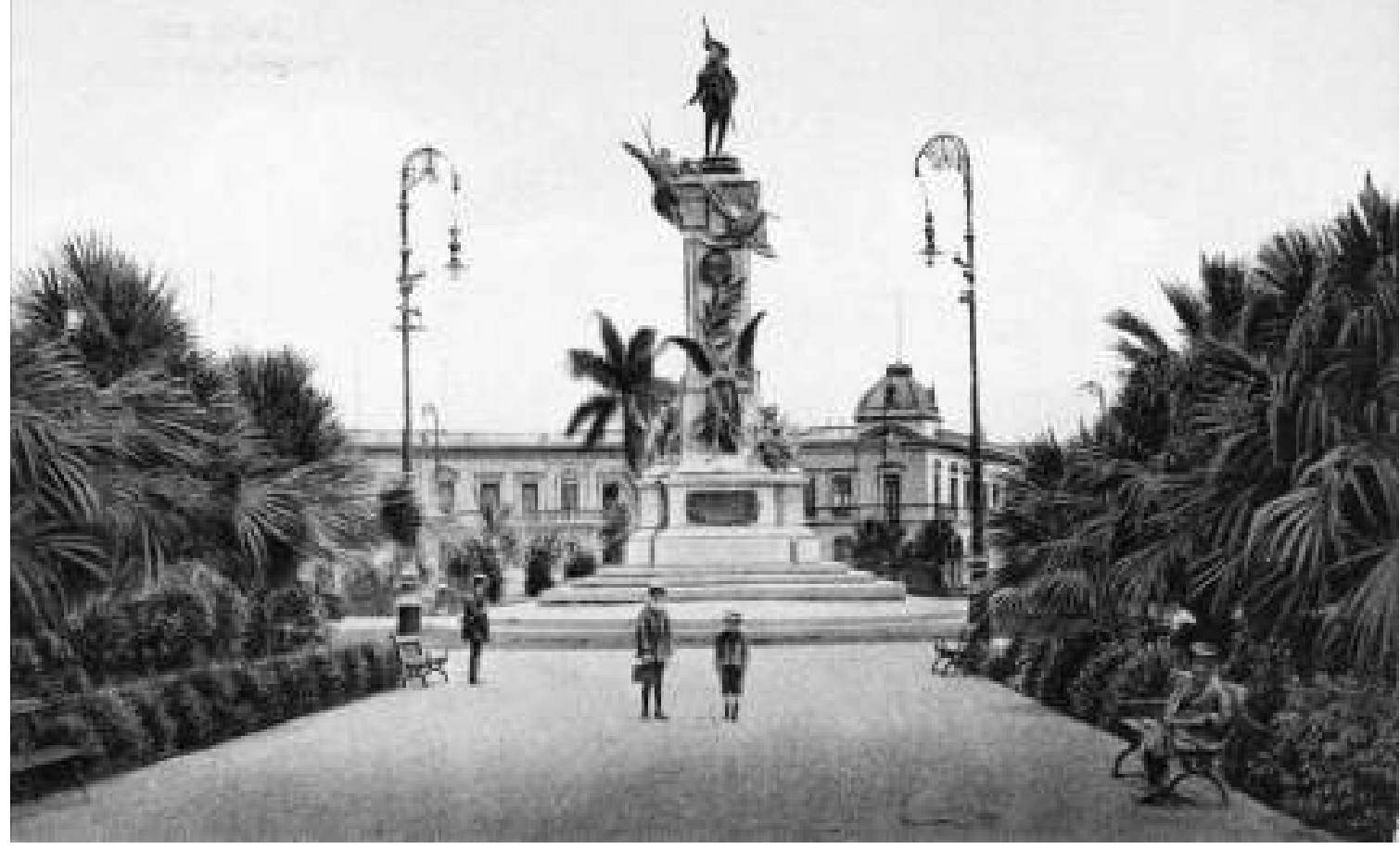

Imagen 13. Plaza Bolognesi, Lima. Imagen de la primera mitad del siglo XX. Fuente: facebook.com/limantigua

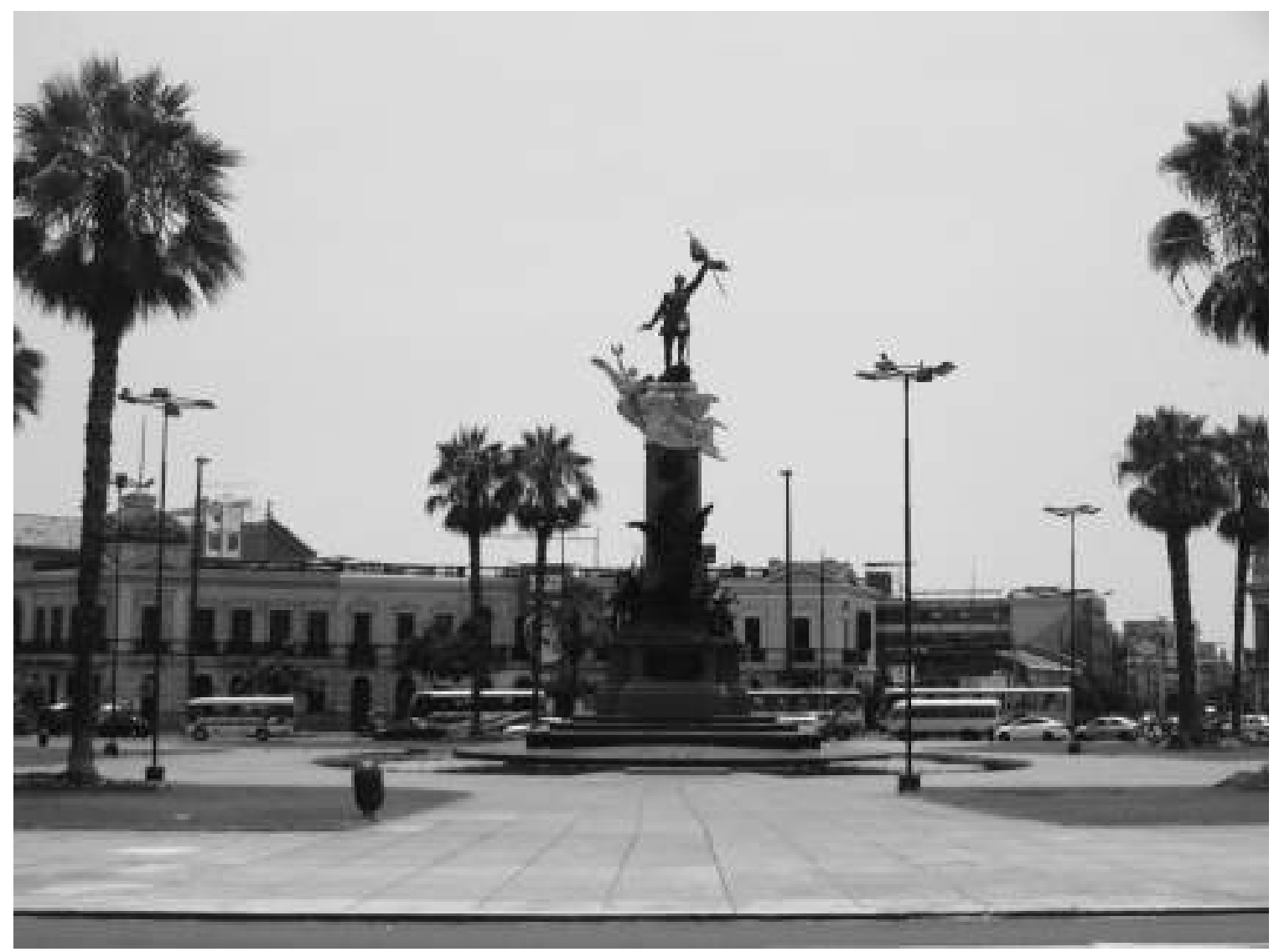

Imagen 14. Plaza Bolognesi, Lima. Foto Elio Martuccelli, 2020.

Alfonso Ugarte eran tres: Libertad-Cinco Esquinas, Cocharcas-Jesús María y Breña-Limoncillo-Portada de Guía.

Recuerdo que en el paradero de la avenida Bolivia, en la acera del Cuartel Sexto, una mañana de 1957 o quizás 1958, coincidí con el vate Javier Heraud. "He renunciado al Movimiento Social Progresista", me dijo, "ahora estoy por el Socialismo Científico". (Algo perplejo, mentalmente me hice el propósito de consultar con Augusto Salazar Bondy qué era el socialismo científico). "Mañana viajo a Cuba, aprovecho para despedirme", terminó. Nos estrechamos la mano, o nos abrazamos, antes de subir él a su bus. No lo vi más. Tiempo des- 
pués en la selva de Madre de Dios murió "entre pájaros y árboles", como premonitoriamente lo anunciara en su hermoso poema El río.

Lima aceleró su crecimiento a partir de la década de 1940. Los tranvías, medio de transporte eficiente, seguro y no contaminante, disminuyeron su servicio por la competencia de uno nuevo, ofrecido por ómnibus municipales subvencionados, que al promediar la década de 1960 dejaron de circular. Un poco antes, durante el gobierno del general Odría, la Plaza Bolognesi sufrió una transformación radical. Los militares, que no entendieron el mensaje que pretendió comunicar el escultor Querol con su héroe, muriendo sí, pero sin soltar ni la bandera ni su arma, obra que había ganado además en un concurso, prefirieron cambiar "un Bolognesi derrotado" (dijeron) por "un Bolognesi valeroso", que lo entendían en posición de ordenar "manos arriba", cambio que corrió casi simultáneo con la eliminación de las palmeras "para que el (amenazante) héroe se vea mejor y para que "el juramento anual de fidelidad a la bandera cada 7 de junio, se luzca como es debido". Aumentó el área pavimentada en perjuicio del área verde y desaparecieron las bancas de clásico diseño en fierro y madera, en las que se descansaba después de patinar y se aprendía a dar los primeros besos de adolescentes enamorados. (Imagen 14)

En el otro extremo, la Plaza 2 de Mayo inició también su transformación en otro sentido. Los departamentos que diseñara Malachowski empezaron a cambiar de usuarios, unos se tugurizaron y otros se dedicaron a oficinas. Pero el hecho más significativo se dio con el uso de un piso de estratégica ubicación para la Central General de Trabajadores del Perú, CGTP, que convirtió la plaza en ágora de asambleas y vigilias frecuentes y en punto de partida de manifestaciones, protestas y marchas, usos que persisten hasta hoy, pese a los problemas de tránsito vehicular que le generan a la ciudad. (Imagen 15)

Entre las dos plazas hay también cambios. El Colegio Rosa de Santa María se muda a un nuevo local en Breña y el que deja es tomado por "el Partido del Pueblo", la Alianza Popular Revolucionaria Americana (APRA), en tanto que en las vecindades de la Plaza Bolognesi se instala la Democracia Cristiana, convertida más tarde en el Par-

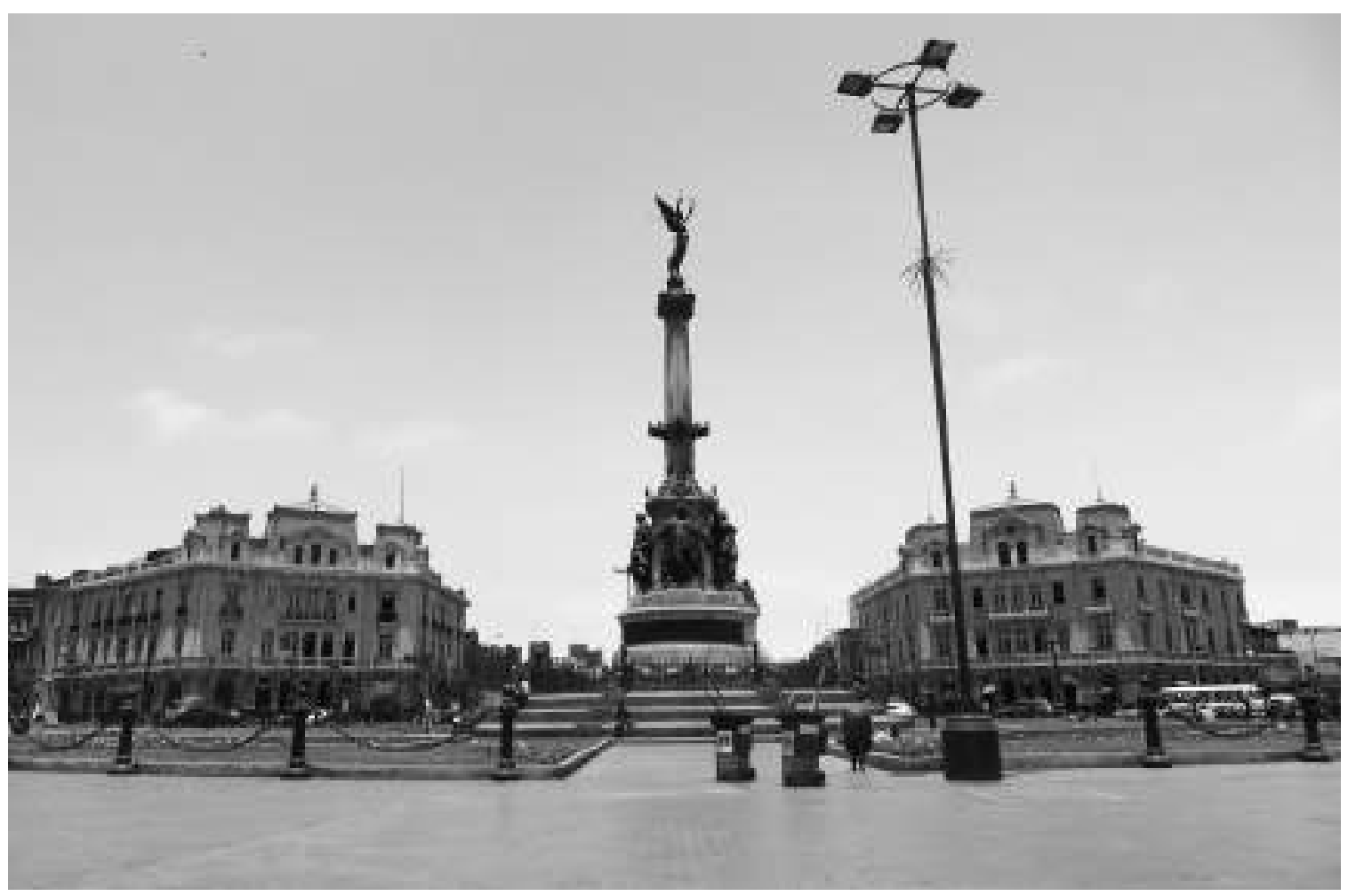

Imagen 15. Plaza Dos de Mayo, Lima. Foto Elio Martuccelli, 2015. 

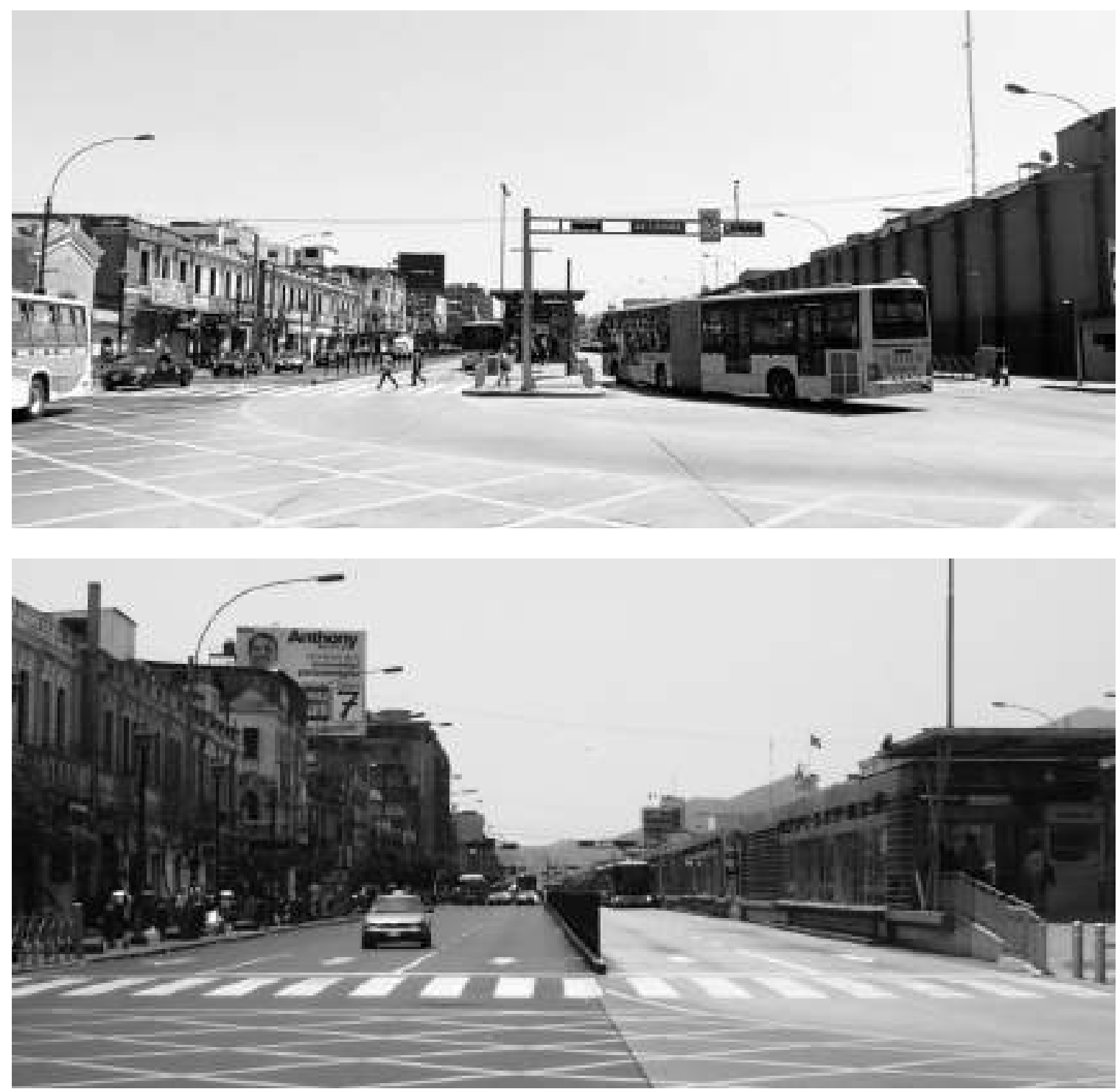

Imágenes 16 y 17. Avenida Alfonso Ugarte. Lima. Vista del corredor central y de la Estación España. Fotos: Dina García, Elio Martuccelli, 2020.

tido Popular Cristiano. La quinta Boza, en cuyo jardín privado jugábamos fútbol hasta que nos botaban para seguir jugando en la entonces desierta avenida Floral, desapareció para dar lugar a locales comerciales y departamentos en varios pisos. Y el Cuartel Sexto que ganara fama como tenebrosa prisión de políticos, cambió su fachada roja de ladrillo visto por un triste revestimiento de cemento, de un gris más triste que el cielo limeño.

La estructura misma de la avenida, su perfil transversal, sufre su transformación más radical durante el mandato del alcalde aprista Jorge Del Castillo, que siguió mal entendiendo los planes del alcalde socialista
Alfonso Barrantes, su antecesor. Por necesidades del tránsito vehicular, la alameda de verdes y arboladas bermas con hermosos jacarandás, debía convertirse en un "corredor vehicular", que implicaba anchar las calzadas sacrificando los jardines y correr a todo lo largo una valla metálica, parecida a los cercos alambrados de los campos de concentración, para evitar que los viandantes crucen las vías por cualquier lado que no sea las esquinas. Pero no es todo. Alfonso Ugarte como víacorredor ha tenido, además, que hundirse en el terreno antes de llegar a la Plaza 2 de Mayo para que los vehículos pasen por debajo del monumento a fin de superar las congestiones que se producían en ese óvalo. 
Alfonso Ugarte, la avenida - paseo de mis años maravillosos, de la época del mambo, del tiempo de las "seriales" dominicales, contemporánea de los cortos de Chaplin y de las películas de charros, de Libertad Lamarque y de Hugo del Carril, cómo se le extraña. Ahora hay que recorrerla con los ojos irritados por el ambiente contaminado, con olor a gasolina y con los oídos martirizados por el claxon de taxis y microbuses y silbatos de policías. Antaño límite externo de la ciudad se halla ahora en su mero centro, convertida en tramo importante del eje que la comunica de sur a norte. (Imágenes 16-23) Cómo se añora sus apacibles áreas verdes, sus bancas de duro y frío mármol de Carrara y sus baños públicos, inútiles para lo que fueran construidos, pero hábiles para contemplar la perspectiva de árboles, desde su azotea con baranda de ba- laustres; o para encaramarse en ella intentando volar cometa o descolgarse huyendo del compañero de juegos. El tiempo pasa y lo transforma todo para bien o para mal, como en este caso. Queda el recuerdo de lo bella, tranquila y acogedora que una vez fue, y que, además, la imaginación puede a veces mejorar. (Imagen 24)

El alcalde Luis Castañeda, sucesor de Del Castillo en realizar "corredores", terminó la destrucción de la avenida Alfonso Ugarte y culminó la construcción de la nueva muralla en su lugar. Porque la vía del Metropolitano, cuyos largos andenes y paraderos de ofensiva arquitectura y los veloces vehículos humeantes que recorren su eje, son otra vez la muralla pero en movimiento, mal usando materiales y lenguaje del siglo XXI.

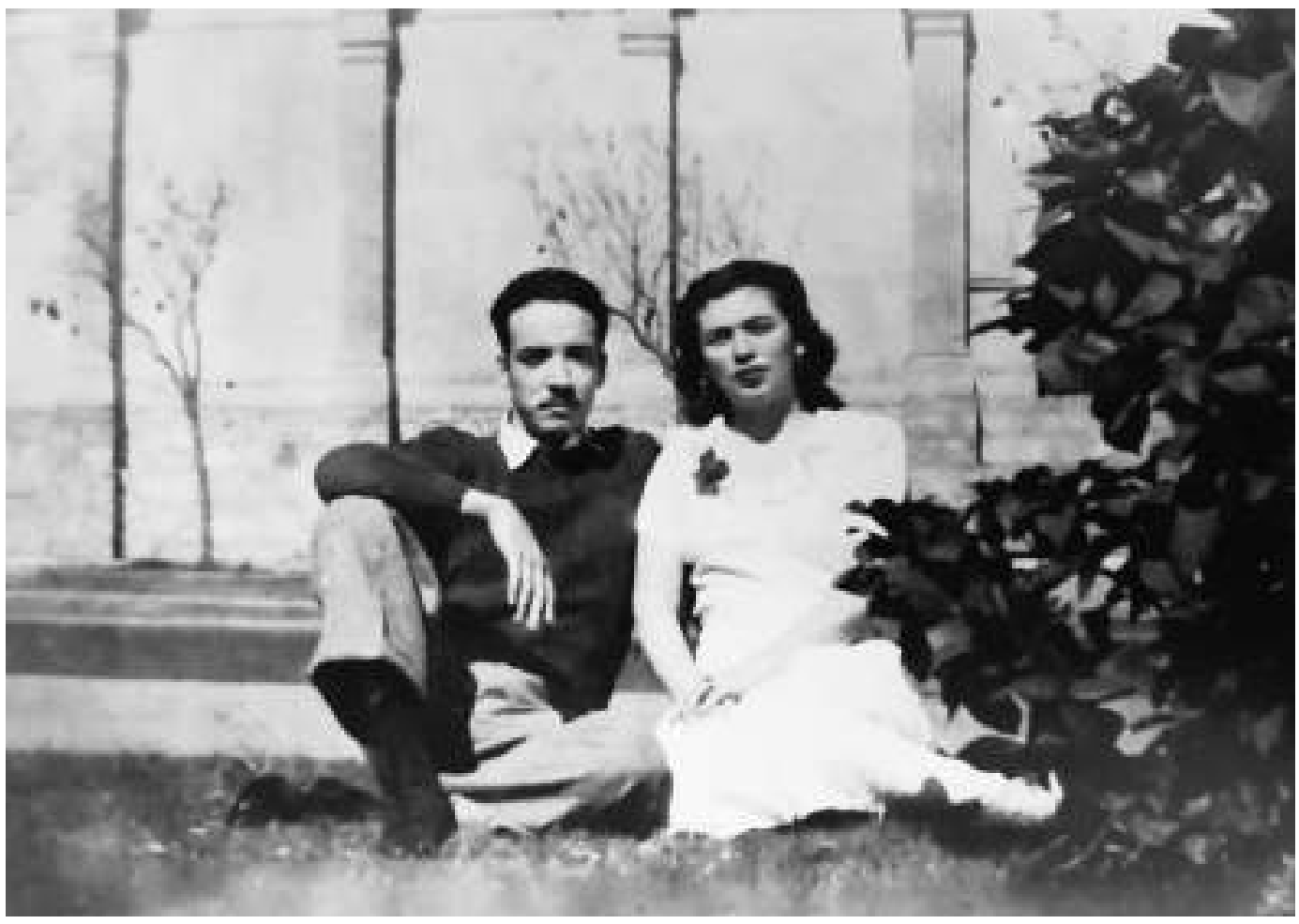

Imagen 24. El autor con su esposa Elsa Cayo, de quien enviudó. Espacio verde de la berma central en la entonces apacible avenida Alfonso Ugarte, al fondo el Cuartel Sexto.

Foto a inicios de la década de 1950. Archivo Adolfo Córdova.

\section{Nota}

1 Como anécdota relatada por el propio autor, traslado aquí la historia del cambio de nombre: la avenida Floral se convirtió en República de Portugal como consecuencia de un pedido formulado por el embajador de Italia. Sucede que en La Victoria existía todo un jirón dedicado a la prostitución, llamado "20 de setiembre". El embajador italiano gestionó cambiar su nombre pues el que tenía hería el honor de su país: el 20 de septiembre de 1870 fue el evento final del largo proceso de unificación italiana. El Alcalde de Lima accedió y le puso avenida Floral. Los vecinos de Breña protestaron, por la confusión que generaba usar el mismo nombre: la solución fue llamarla entonces Portugal, probablemente por estar al lado de la avenida España. (Nota del editor) 